\title{
PAGAMENTO DE SERVIÇOS AMBIENTAIS: UMA ANÁLISE SOBRE SÜA IMPLANTAÇÃO
}

\author{
PAYMENT OF ENVIRONMENTAL SERVICES: AN ANALYSIS OF ITS IMPLEMENTATION
}

\author{
PAGO DE SERVICIOS AMBIENTALES: ANÁLISIS DE SU IMPLEMENTACIÓN
}

Juliana Paula Sá Carneiro ${ }^{1}$

Joyce Silvestre de Sousa ${ }^{2}$

\section{Resumo}

O presente trabalho faz uma análise do Pagamento por Serviços Ambientais (PSA), um instrumento econômico que possui destaque nas políticas ambientais — devido ao aumento da preocupação com o meio ambiente e da sua preservação. No Brasil, o Pagamento por Serviços Ambientais foi instuído na legislação federal brasileira através do Novo Código Florestal (Lei 12651/2012). A pesquisa tem cunho exploratório e bibliográfico, com exame de casos sobre o Pagamento por Serviços Ambientais no mundo e no Brasil. Os artigos utilizados na investigação demons traram que a aplicação do PSA auxilia na preservação ambiental.

Palavras-chave: Alternativas. Conservação ambiental. Pagamento por serviços ambientais. Práticas ambientais. Propostas.

\begin{abstract}
This paper analyzes the Payment for Environmental Services (PES), an economic instrument that stands out in environmental policies - due to the increased concern for the environment and its preservation. In Brazil, payment for environmental services was instuated in the brazilian federal legislation through the New Forest Code (Law 12651/2012). The research has an exploratory and bibliographic nature, with an examinaton of Payment for Environmental Services cases in the world and in Brazil. The articles used in the research demonstrated that the application of PES helps in environmental preservation.
\end{abstract}

Keywords: Alternatives. Environmental conservation. Payments for ecosystem services. Environmental practices. Proposals.

\section{Resumen}

Este trabajo analiza el Pago por Servicios Ambientales (PSA), instrumento económico de destaque en las políticas ambientales, dado el aumento de la preocupación con el medio ambiente y su preservación. En Brasil, el Pago por Servicios Ambientales se instituye en la legislación federal brasileña por medio del Nuevo Código Forestal (Ley 12651/2012). Esta es una investigación exploratória y bibliográfica, con estudio de casos sobre el Pago por Servicios Ambientales en Brasil y en el mundo. Los artículos utilizados en el estudio demostraron que la aplicación del PSA sirve de apoyo a la preservación ambiental.

Palabras-clave: Alternativas. Preservación ambiental. Pago por servicios ambientales. Prácticas ambientales. Propuestas.

\section{Introdução}

A preservação ambiental tem alcançado importância cada vez maior devido aos níveis de degradação ambiental — que se intensificam cada vez mais. Com o a compreensão da

\footnotetext{
${ }^{1}$ Pós Graduanda em Saneamento Ambiental - Instituto Federal do Triângulo Mineiro. E-mail: julliannasa@gmail.com.

${ }^{2}$ Doutorado em Recursos Hídricos pela Universidade Federal de Lavras. E-mail: joyce@iftm.edu.br.
} 
importância da preservação ambiental, surge a necessidade de atribuir responsabilidades pelas externalidades. Essas externalidades são os efeitos não intencionais de decisões de produção e consumo de um agente, que podem gerar custos (perdas) ou benefícios (ganhos) de bem-estar de outro agente econômico (CAETANO; MELO; BRAGA, 2016). A precificação dos serviços ambientais pode ser feita através de vários instrumentos econômicos de políticas ambientais, sendo um deles o Pagamento por Serviços Ambientais (PSA) (GODECKE; HUPFFER; CHAVES, 2014).

O PSA é uma tendência mundial recente e inovadora que tem por finalidade fazer os beneficiários de serviços ambientais compensarem os agentes responsáveis pela geração do serviço, tendo em vista o desenvolvimento sustentável (GODECKE; HUPFFER; CHAVES, 2014). Essa compensação pode ser feita através do pagamento em dinheiro, isenção de impostos, concessão de crédito diferenciado, entre outros (SOUSA, 2017). Vários países consideram o PSA em suas políticas públicas, de modo a conciliar o desenvolvimento econômico com o socioambiental - o que traz resultados satisfatórios. No Brasil, o PSA ganhou força na forma da Lei 12.651/2012 (BRASIL, 2012), conhecida como Novo código Florestal, o que instituiu formalmente esse mecanismo na Legislação Federal Brasileira.

O objetivo desse trabalho foi analisar o "estado da arte" sobre o tema pagamento por serviços ambientais por meio de pesquisa exploratória e bibliográfica de modo a proporcionar maior entendimento sobre o assunto. De acordo com Malhotra (2001), o enfoque exploratório e bibliográfico possibilita a compreensão do problema enfrentado pelo pesquisador, definindoo com maior precisão e identificando cursos relevantes.

\section{Desenvolvimento}

A exploração dos recursos naturais é fundamental para a sobrevivência humana e permitiu o desenvolvimento da sociedade ao longo dos séculos; entretanto, à medida que desenvolvimento industrial e tecnológico aumentava, a partir da revolução industrial, crescia também o consumo e a exploração dos recursos naturais. O resultado dessa exploração desenfreada e do crescimento do consumo é a degradação do meio ambiente; logo, se nenhuma atitude for tomada, as consequências dessa degradação serão visíveis e catastróficas (PENSAMENTO VERDE, 2014).

Entre 2001 e 2005 foi realizada a Avaliação Ecossistêmica do Milênio (AEM), a maior avaliação sobre a saúde dos ecossistemas já realizada, que contou com o envolvimento de cerca de 1360 especialistas de 95 países. Identificou-se, na avaliação, que cerca de 60\% (15 entre 24) 
dos serviços dos ecossistemas têm sido degradados ou utilizados de forma não sustentável (MILLENNIUM ECOSYSTEM ASSESSMENT, 2005).

A precificação de um bem ou serviço ambiental pode ser feita a partir dos diferentes tipos de uso (FERNANDEZ, 2010):

- Valor de uso direto (VUD), quando o indivíduo se utiliza atualmente de um recurso;

- Valor de uso indireto (VUI), quando o benefício atual do recurso deriva das funções ecossistêmicas;

- Valor de opção (VO), quando se atribui valor em usos direto e indireto que poderão ser optados em um futuro próximo e cuja a preservação pode ser ameaçada;

- Valor de não ou de existência (VE), associado a questões éticas, morais, culturais ou altruístas.

Dentre os diversos instrumentos econômicos de políticas ambientais que surgiram para internalizar o custo das externalidades, destaca-se o Pagamento por Serviços Ambientais (PSA) (CAETANO; MELO; BRAGA, 2016). De acordo com Wunder (2005), o PSA é definido como a transferência financeira de beneficiários de serviços ambientais para o que, devido a práticas que conservam a natureza, fornecem esses serviços de forma segura e bem definida, por meio de uma transação voluntária.

Dentre os componentes básicos que caracterizam um processo de PSA temos (WUNDER, 2005, p. 3 apud CAETANO; MELO; BRAGA, 2016, p. 119):

- Voluntariedade;

- Serviço ambiental bem definido, que pode ser um serviço a ser comercializado , por exemplo, ou um uso da terra capaz de prover o serviço;

- Demandantes - que podem ser um voluntário, o governo ou estabelecido pela definição dos direitos de propriedades;

- Provedores - que se comprometam em gerar e manter os serviços, através de práticas de preservação, proteção e manejo dos recursos naturais;

- Condicionalidade, que é o critério mais difícil de ser alcançado devido às complexidades biofísicas ligadas aos ecossistemas e seus processos, que dificultam a comprovação da relação de causalidade entre os diversos usos da terra.

O pagamento por serviços ambientais possuem dois objetivos principais de acordo com Alteman e Reach (2009). O primeiro, de caráter didático, tem por fim conscientizar os beneficiários dos serviços ambientais sobre sua importância. O segundo é valorizar quem contribui diretamente para sua preservação.

Existem diversas modalidades de PSA que podem incluir a comercialização de créditos de carbono, o ICMS ecológico, compensação ambiental, reposição florestal, isenção de impostos, concessão de créditos diferenciados, programas de assistência técnica, entre outros 
(SOUSA, 2017).

O PSA está formalmente instituído na legislação federal brasileira. No capítulo décimo da Lei 12.651/2012 está previsto o pagamento ou incentivo a serviços ambientais como retribuição, que pode ser monetária ou não, às atividades de conservação e melhoria dos ecossistemas que gerem serviços ambientais, como: o sequestro, a conservação, a manutenção e o aumento do estoque e a diminuição do fluxo de carbono, a conservação da beleza cênica natural, da biodiversidade, das águas e dos serviços hídricos e do solo, regulação do clima, a valorização cultural e do conhecimento tradicional ecossistêmico e a manutenção de Áreas de Preservação Permanente (APP), de Reserva Legal (RL) e de uso restrito (BRASIL, 2012).

Um dos principais programas de PSA no Brasil é o Programa Produtor de Águas (PPA), lançado pela Agência Nacional de Águas (ANA) em 2001 - fundamentado na Política Nacional de Recursos Hídricos (BRASIL, 1997). O PPA é um programa de controle da poluição difusa rural, voltado principalmente para as bacias hidrográficas de importância estratégica para o país. É de adesão voluntária para produtores rurais que se proponham a adotar práticas e manejos conservacionistas em suas terras para preservação de solo e água. E, como os benefícios dessas práticas ultrapassam os limites das propriedades rurais e chegam aos demais usuários da bacia, os produtores participantes são remunerados proporcionalmente ao serviço ambiental prestado, mediante a prévia inspeção da propriedade (EMATER, 2018).

Os principais objetivos do programa, segundo o Manual Operativo do PSA são (ANA, 2008):

- Difundir e discutir o mercado de serviços ambientais, explicitando produtos ecossistêmicos gerados através da ação antrópica sobre bacias hidrográficas;

- Aumentar a oferta de água nas bacias hidrográficas por meio da adequada alimentação do lençol freático a ser obtida com o uso de práticas mecânicas e vegetativas que aumentem a infiltração de água no solo;

- Reduzir os níveis de poluição difusa rural em bacias hidrográficas estratégicas para o país, principalmente aqueles decorrentes dos processos de erosão, sedimentação e eutrofização;

- Difundir o conceito de manejo integrado do solo e da água através da conscientização e do incentivo à implantação de práticas e manejos conservacionistas e da preservação e recuperação de florestas nativas;

- Garantir a sustentabilidade sócio-econômica e ambiental dos manejos e práticas implantadas, por meio de incentivos financeiros aos agentes selecionados.

Um dos primeiros projetos realizados em parceria com o Programa Produtor de Água é o Programa Conservador de Águas do município de Extrema (MG), que foi lançado em 2003 e analisado por Jardim e Bursztyn (2015). Localizada na Serra da Mantiqueira, na divisa entre Minas Gerais e São Paulo, Extrema possui uma área rural com grande quantidade de nascentes 
e pequenos cursos d'água que alimentam o Sistema Cantareira — que abastece a Grande São Paulo.

O município participou entre 1996 e 1998 do Projeto de Execução Descentralizada, do Programa Nacional de Ambiente. Desse projeto, nasceu em 1999 o Projeto Água é Vida, com o intuito do manejo das bacias hidrográficas da região. Entretanto, devido à falta de um diagnóstico ambiental, não foi possível executar qualquer plano de manejo. Em 2001, a prefeitura subsidiou um estudo completo na região com o intuito de elaborar ações direcionadas à proteção do meio ambiente. $\mathrm{O}$ diagnóstico socioambiental mostrou que as áreas de florestas estavam sendo substituídas pela agropecuária. Apontou-se, também, a degradação do solo, a perda da biodiversidade e a diminuição da renda do produtor rural; além disso, como o Projeto Água é Vida realizou um trabalho de melhorias das estradas rurais com a construção de bacias de contenção e monitoramento dos principais cursos d'água do município, foi efetivada a parceria com o Programa Produtor de Água.

Em 2003, iniciou-se o Programa Conservador das Águas, com o objetivo de aumentar a cobertura vegetal nas sub-bacias hidrográficas e implantar microcorredores ecológicos, reduzir os níveis de poluição rural difusa decorrentes dos processos de sedimentação e eutrofização e de falta de saneamento ambiental; difundir o conceito de manejo integrado de vegetação, solo e água na bacia do Rio Jaguari e garantir sustentabilidade socioeconômica e ambiental dos manejos e práticas implantadas, por meio de incentivos financeiros aos proprietários rurais. O programa conta com parcerias do setor público, como o ANA, IEF, Comitê do PCJ e do setor privado, como o SABESP, TNC e SOS Mata Atlantica. Esses orgãos se comprometeram a apoiar as ações de campo e deixaram sob responsabilidade da prefeitura as despesas referentes aos pagamentos dos proprietários rurais e à condução administrativa e técnica do programa. A remuneração acontece de forma proporcional em relação à área total da propriedade e não apenas pela área conservada - o que enfatiza a importância da adequação propriedade como um todo (JARDIM; BURSZTYN, 2015).

Pinto et al. (2015) realizaram uma avaliação da eficiência do uso do ICMS ecológico como política pública de PSA na preservação das Unidades de Conservação (UCs) do Mato Grosso do Sul, entre 2002 e 2014. No estado, até 5\% do ICMS pode ser utilizado como ferramenta de incentivo à proteção da natureza e manutenção da biodiversidade; contudo, os municípios precisam atender dois critérios para o recebimento desse incentivo: a adoção e a existência de ações públicas efetivas no tratamento de resíduos sólidos e o estado satisfatório das UCs.

O estudo mostrou que após 13 anos da implantação do ICMS ecológico houve um 
crescimento considerável da área das UCs em relação à área total dos municípios, assim como dos valores repassados. Entretanto, na maior parte dos municípios encontram-se com os níveis de eficiência de manejo e conservação abaixo do esperado, devido a insuficiência na adoção de políticas de conservação.

Já em relação a iniciativas de grupos privados, está o Projeto Oásis da Fundação Grupo Boticário de Proteção à Natureza. Lançado em 2006, na cidade de São Paulo, com o intuito de contribuir com a redução da perda da biodiversidade, o projeto conta atualmente outros seis programas de PSA estruturados: Oasis Apucarana (Apucarana/PR), Produtor de Água de Rio Vermelho (São Bento do Sul/SC), Oasis Brumadinho (Brumadinho/MG), Corredores de Biodiversidade (Corredores Timbó e Chapecó/SC) São José Mais Água (São José dos Campos/SP e Produtor de Água Pratigi (Ibirapitanga/BA). O Oasis também conta com 19 parcerias formalizadas. A fórmula de valoração ambiental utilizada é flexível e considera três variáveis principais: características ambientais, sociais e econômicas da região. A metodologia, o sistema e o manual de implantação são repassados gratuitamente para as entidades - prefeituras, comitês de bacias hidrográficas, consórcios, empresas, ONGs, entre outras - que se comprometerem a implantar o projeto. O Grupo O Boticário entra como parceiro técnico, orientando e acompanhando a implementação dos Programas (FUNDAÇÃO GRUPO O BOTICÁRIO, 2018).

O Programa Produtor de Água e Floresta (PAF), que foi implantado no ano de 2009, na bacia do Rio Guandu - localizada em Lídice, distrito de Rio Claro (RJ). O sistema Guandu é responsável por cerca de $80 \%$ do abastecimento da cidade do Rio de Janeiro e o PAF abrange um de seus principais mananciais, o Rio Piraí. O projeto conta com a cooperação técnica entre a Secretaria Estadual do Ambiente (SEA), a Prefeitura Municipal de Rio Claro, a The Nature Conservancy (TNC), o Comitê de Bacia Hidrográfica do Rio Guandu e o Instituto da Terra de Preservação Ambiental (ITPA), com o apoio da ANA e o objetivo é proporcionar o aumento da cobertura florestal em áreas de preservação permanente e demais áreas prioritárias, melhorando a qualidade e a quantidade dos recursos hídricos dos mananciais. O público alvo são os proprietários rurais da região, que são estimulados a adorem práticas para a proteção dos recursos naturais e recuperação de mananciais mediante ao recebimento de compensação financeira. Cada produtor deverá dispor de no mínimo $25 \%$ da área sem cobertura florestal de sua propriedade para restauração. Essa área deverá estar situada em área prioritária ao projeto e o valor pago a cada produtor é calculado com base em quatro parâmetros: tamanho da área destinada a restauração e a conservação, nível de prioridade para produção de água (APPs e áreas interceptadoras de água), estágio de sucessão dos remanescentes em conservação e 
proximidade ou inclusão em áreas de conservação (PAIVA; COELHO, 2015).

Paiva e Coelho (2015) analisaram o perfil e a percepção ambiental dos produtores inscritos no PAF. Participaram da pesquisa 29 dos 58 produtores, que responderam questionamentos referentes ao perfil socioeconômico, motivação para adesão ao PAF e importância da preservação ambiental. Em relação ao perfil socioeconômico, a maioria dos participantes é homem, possui escolaridade e renda familiar acima da média do estado do Rio de Janeiro, além de não residirem e nem possuirem na propriedade a sua principal fonte de renda. Sobre a motivação para adesão ao PAF, 83\% dos produtores declararam que foi a preocupação ambiental e 14\% o retorno financeiro. Apenas 3\% declarou que só concordou em participar devido à imposição dos outros proprietários da propriedade. $49 \%$ afirmaram que a boa assistência técnica oferecida é um fator facilitador para a adesão ao programa e $41 \%$ afirmou que a facilidade se dá pela disponibilidade de informações. Em relação a importância da preservação ambiental, 76\% declararam que a adesão ao PAF contribuiu para a melhoria do ar e da água. Para 10\%, o principal benefício foi a manutenção do habitat para outras espécies. Além disso, 59\% dos entrevistados declaram acreditar que o valor de mercado da propriedade aumentou a partir das ações estabelecidas pelo programa.

Sousa (2017) avaliou, em seu estudo, a aplicabilidade de pagamentos por serviços ambientais na bacia do Rio Claro (MG) e os benefícios ambientais gerados. Um dos problemas existentes na região é a utilização das APP para outros usos. Apesar de 93,24 \% da área estar em conformidade com a legislação, 5,27\% é usada para agricultura e 1,3\% pastagens; além de trazer impactos ambientais negativos aos recursos hídricos e biodiversidade da região, isso torna as propriedades não cumpridoras da legislação vigente. O PSA sugerido para a bacia teve como referência o Programa Produtor de Água e foi denominado Programa ACA (Áreas de Conservação de Água) e teria os governos municipais e outros parceiros, como o Comitê da Bacia Hidrográfica do Rio Araguari, como gestores.

O Programa ACA tem como objetivo aumentar a oferta de água na bacia hidrográfica, redução da poluição difusa rural e treinamento de potenciais agentes executores do programa em relação aos seus critérios e procedimentos. Logo, foram simulados dois cenários: no cenário 1, toda a área das ACAs seria transformada em floresta, e no cenário 2, acrescentaria-se a adoção de práticas conservacionistas e a implantação do programa seria expandida para toda área de agricultura e eucalipto da bacia. O cenário 1 traria 4,4\% de redução na perda de solo da bacia e o cenário 2 traria 84,1\% de redução. Em relação aos custos para a implantação do programas, considerando-se um valor de $\mathrm{R} \$ 254,00$ ha/ano, para o cenário 1, cuja a área equivale a 9746,94 ha, seriam necessários $\mathrm{R} \$ 2486136,13$ por ano. Já para o cenário 2, com uma de 
91647,14 ha, seriam necessários R $\$ 23278373,27$ por ano para a implementação do programa. Os recursos para a implantação do programa poderiam vir principalmente do valor arrecadado pela cobrança pelo uso da água, já instalado na Bacia do Rio Araguari, que tem o Rio Claro como afluente e dos Termos de Ajustamento de Conduta (TACs) firmados entre o Ministério Público de Uberaba e região. Além de recompensa financeira, também são propostas outras formas de incentivo para os participantes do programa, como assistência técnica, a concessão de crédito diferenciado e a certificação dos produtos.

Maia (2015) realizou uma pesquisa amostral, utilizando-se de um questionário socioeconômico, nos municípios de Campinas e de Arthur Nogueira.

\footnotetext{
O objetivo principal da pesquisa era captar a máxima DAP da população pelos benefícios ambientais do "Projeto de Pagamentos por Serviços Ambientais no Corredor das Onças - remuneração pela conservação de Puma concolor mediante adequação ambiental em propriedades rurais na Região Metropolitana de Campinas (RMC). (MAIA, 2015, p. 103).
}

Foram avaliados 2 cenários: o primeiro, sem corredor ecológico, contemplando valores de uso associados a retenção e aproveitamento de água da chuva, regulação da oferta de água no ambiente, prevenção do assoreamento dos rios, redução do desmoronamento e das enchentes nas áreas urbanas, regulação da qualidade da água, absorvendo parte da poluição dos rios. $\mathrm{O}$ segundo, com corredor ecológico, consideram-se os valores de não uso associados à manutenção de um corredor biológico para espécies vegetais e animais que habitam a bacia. Não houve diferença significativa entre as DAPs para os dois tipos de cenário. O autor apresenta como uma justificativa para esse resultado o fato da dificuldade de distinção entre os dois tipos de cenário pelos entrevistados e a dificuldade do método para captar a DAP que reflita a real utilidade dos atributos avaliados. A DAP mensal estimada para Campinas foi de R $\$ 9,39$ (DAP Anual de R \$ 39.897.533) e de R \$11,80 para Arthur Nogueira (DAP Anual de R\$ 1.975.787). Uma das justificativas para a DAP de Arthur Nogueira ser superior por causa da oferta de água, já que o município depende de suas próprias fontes para abastecimento público. O valor da DAP também é influenciado pelo rendimento domiciliar, sendo que pessoas que não declararam a renda ou que tem rendimentos baixos (até $\mathrm{R} \$ 800$ mensais) tem menor propensão a pagar. Outro fator influenciador é o grau de preocupação ambiental, que contribui para uma DAP maior.

Araújo Junior \& Ciciliato (2012) e Pereira \& Alves Sobrinho (2017) analisaram casos de PSA no mundo. Em Chiapas, região sul do México, há o projeto Scolel’Té, criado em 1997, que remunera o sequestro de carbono. Os beneficiários são as comunidades indígenas 
proprietárias das áreas florestais que recebem incentivos econômicos para proteger e manejar de maneira sustentável a sua propriedade. O pagamento é feito por meio de fundos (Fundo Bioclimático e Plan Vivo) criados para gerir os recursos arrecadados com a venda dos créditos de carbono lançado no mercado internacional. Atualmente, em 2019, de acordo com o PlanVivo (PLAN VIVO, 2019), participam do programa mais de 1200 pequenos proprietários.

A Costa Rica, um dos países pioneiros no pagamento por serviços ambientais, implementou em 1996 o atual PSA-CR para tentar controlar os altos índices de desmatamento. Em 18 anos, a cobertura florestal aumentou de $21 \%$ para $51 \%$. O financiamento é feito através do FONAFIFO - Fundo Nacional de Financiamento Florestal, alimentado inicialmente por impostos sobre combustíveis fósseis, que remunera os proprietários rurais que conservam e restauram a floresta nativa. O FONAFIFO também é alimentado pelas contribuições financeiras estatais recebidas pelos orçamentos ordinários e extraordinários da República, doações ou créditos recebidos de organizações nacionais e internacionais e empresas privadas locais (ARAÚJO JUNIOR; CICILIATO, 2012; PEREIRA; ALVES SOBRINHO, 2017).

Em Nova York, nos Estados Unidos, foi criado um plano de manejo dos mananciais de água da Bacia de Catskill, responsável por cerca de $90 \%$ da água da cidade. Ao invés de investir em estações de tratamento de água, que necessitariam de um investimento inicial de US\$ 6 bilhões e US\$ 250 milhões para operação e manutenção, a cidade preferiu investir US\$ 1,5 bilhão, por um período de 10 anos, em um plano de proteção ambiental que garantisse a qualidade da água dos mananciais e não precisassem de filtragem. A prefeitura financia os produtores rurais da montanhas de Catskill e investe em infraestrutura em troca da conservação dos mananciais. Até hoje Nova York e algumas cidades vizinhas não necessitam instalar estação de tratamento de água. A água é clorada e fluoretada e o escoamento ocorre por gravidade. A economia total do projeto chega a US\$ 10 bilhões em 20 anos (PEREIRA; ALVES SOBRINHO, 2017; ARANTES, 2014).

Sobre as dificuldades de se implementar os PSA, Wunder (2006 apud GODECKE; HUPFFER; CHAVES, 2014, p. 24).

a demanda limitada, decorrente da falta de voluntariedade para estes pagamentos; inexistência de precondições institucionais exigidas pelas partes para negociação, cumprimento de contratos e garantias para, por exemplo, comunidades pobres e remotas; e dificuldades de comunicação, pois quem propõe os programas de PSA costuma utilizar- se de linguajar inacessível aos povos locais.

No trabalho de Paiva e Coelho (2015), ao serem questionados sobre as dificuldades de 
implantação do PAF, 66\% dos entrevistados não conseguiram apontar nenhuma e 17\% citaram a burocracia como fator dificultador. Pinto et al. (2015) verificou que a maior parte dos municípios do Mato Grosso do Sul não mantêm uma política adequada de reciprocidade do PSA do ICMS Ecológico em ações para manutenção das unidades de conservação, tornando difícil essas UCs manterem níveis satisfatórios crescentes de conservação dos recursos naturais. Dessa forma, percebe-se que para um PSA seja bem implementado é de grande importância a participação do poder público e que seja estabelecido uma comunicação acessível para todos os envolvidos.

\section{Considerações finais}

A partir dos casos apresentados, nota-se que o PSA é um instrumento de gestão que vem sendo cada vez mais incorporado nas políticas públicas, com bons resultados no mundo e no Brasil. Como a legislação federal brasileira já reconhece a importância dos PSA, a tendência é que esse mecanismo se fortaleça e seja aplicado cada vez mais, potencializando ações de conservação ambiental e incentivando os produtores de serviços ambientais a adotar práticas mais sustentáveis.

Destaca-se o fato de o investimento em boas práticas ambientais traz resultados excelentes, como mostrado no caso do PSA de Nova York, em que houve uma economia significante devido ao manejo dos mananciais de Bacia de Catskill. Infelizmente, muitas vezes, não é realizado um planejamento a longo prazo e os gastos com políticas ambientais é visto como despesa, e não como um investimento. Por isso, grande parte das ações no âmbito ambiental são executadas de maneira corretiva.

Como visto na pesquisa realizada com os moradores de Campinas e Arthur Nogueira, a população tem interesse em pagar pelos benefícios dos serviços ambientais, o que indica que a captação de demandantes não é um fator dificultador.

Já na pesquisa realizada com os participantes do Programa Produtor de Água e Floresta (PAF), o fato da maioria dos participantes não morar e não ter na propriedade a sua principal fonte de renda pode demonstrar uma maior propensão desses produtores rurais em aderir ao programa, pois as preocupações e incertezas em relação ao futuro seriam, tecnicamente, menores.

Também é bom frisar que, para que a implementação do PSA tenha êxito, é necessário que os participantes tenham apoio, incentivo e acompanhamento dos órgãos gestores, sejam esses públicos ou privados, não apenas no início do processo; ademais, a comunicação deve ser 
apropriada e acessível ao público que se destina.

Além disso, o incentivo à adoção de práticas sustentáveis deve ser feito não só através de pagamento em dinheiro, mas também por meios não monetários, como isenção de impostos, concessão de créditos diferenciados e programas de assistência técnica.

\section{Referências}

ANA (Agencia Nacional de Águas). Manual operativo: produtor de Água. 2008. Disponível em: http://produtordeagua.ana.gov.br/Portals/0/DocsDNN6/documentos/MANUAL\%20OPERA TIVO\%20-\%20PROGRAMA\%20PRODUTOR\%20DE\%20\%C3\%81GUA.pdf. Acesso em: 16 out. 2008.

ALTEMANN, Alexandre; RECH, Adir Ubaldo. Pagamento por serviços ambientais: imperativos jurídicos e ecológicos para a preservação e a restauração das matas ciliares. Caxias do Sul, RS: Educs, 2009. 61 p.

ARANTES, Adriana. Melhores práticas: a multiplicação das águas. Revista Desafios do Desenvolvimentos, Minas Gerais, v. 79, n. 10, 2014. Disponível em: http://www.ipea.gov.br/desafios/index.php?option=com_content\&view=article\&id=3021:C atid=28\&Itemid=23. Acesso em: 28 fev. 2019.

ARAÚJO JUNIOR, Miguel Etinguer de, CICLIATO, Rodolfo Xavier. Os pagamentos por serviços ambientais (psa) como alternativa na construção da sustentabilidade ambiental em países europeus e americanos. Revista Eletrônica Direito e Política, Itajaí, v. 7, n. 1, 2012. Disponível em: https://siaiap32.univali.br/seer/index.php/rdp/article/view/5662/3062. Acesso em: 28 out. 2018.

BRASIL. Lei no 9.433, de 8 de janeiro de 1997. Institui a Política Nacional de Recursos Hídricos, cria o Sistema Nacional de Gerenciamento de Recursos Hídricos, regulamenta o inciso XIX do art. 21 da Constituição Federal, e altera o art. $1^{\circ}$ da Lei $\mathrm{n}^{\circ} 8.001$, de 13 de março de 1990, que modificou a Lei n ${ }^{\circ} 7.990$, de 28 de dezembro de 1989. Brasília:

Presidência da República Casa Civil, 1997. Disponível em: http://www.planalto.gov.br/ccivil_03/leis/19433.htm. Acesso em: 16 out. 2018.

BRASIL. Lei no 12.651, de 25 de maio de 2012. Dispõe sobre a proteção da vegetação nativa; altera as Leis ${ }^{\circ}$ s 6.938 , de 31 de agosto de 1981, 9.393, de 19 de dezembro de 1996, e 11.428, de 22 de dezembro de 2006; revoga as Leis $n^{\circ}$ s 4.771, de 15 de setembro de 1965, e 7.754, de 14 de abril de 1989, e a Medida Provisória no 2.166-67, de 24 de agosto de 2001; e dá outras providências. Brasília: Presidência da República, 2012. Disponível em: http://www.planalto.gov.br/ccivil_03/_ato2011-2014/2012/lei/112651.htm. Acesso em: 16 out. 2018.

CAETANO, Patrícia Pereira; MELO, Maiara Gabrielle de Souza; BRAGA, Cybelle Frazão Costa. Pagamento por Serviços Ambientais (PSA): análise de conceitos e marco regulatório. Revista Princípia, João Pessoa, n. 31, 2016.

EMATER (Empresa de assistência técnica e extensão rural do estado de MG). Programa Produtor de Água. 2018. Disponível em: http://www.emater.df.gov.br/wp- 
content/uploaDs/2018/04/programa-prod-agua.pdf. Acesso em 13 out. 2018.

FERNANDEZ, Rodrigo Nobre. Anexo I - O valor econômico dos recursos naturais. 2010. Disponível em: http://www.rodrigofernandez.com.br/ecologica/anexo1.pdf. Acesso em:18 out. 2018.

FUNDAÇÃO GRUPO O BOTICÁRIO. Projeto Oasis: resumo executivo. 2018. Disponível em: https://www.fundacaogrupoboticario.org.br/pt/Biblioteca/Resumo\%20executivo\%20Oasis.pdf. Acesso em: 22 abr. 2019.

GODECKE, MarcosVinicius; HUPFFER, Haide Maria; CHAVES, Iara Regina. O futuro dos pagamentos ambientais no Brasil a partir do novo código florestal. Revista Desenvolvimento e Meio Ambiente, Curitiba, v. 31, p.31-42, 2014. Disponível em:

https://revistas.ufpr.br/made/article/view/34896. Acesso em: 14 out. 2018.

JARDIM, Mariana Heilbuth; BURSZTYN, Maria Augusta. Pagamento por serviços ambientais na gestão de recursos hídricos: o caso de Extrema (MG). Eng Sanit Ambient, Rio de Janeiro, v. 20, n. 3, jul./set. p. 353-360, 2015. Disponível em:

http://www.scielo.br/pdf/esa/v20n3/1413-4152-esa-20-03-00353.pdf. Acesso em 09 out. 2018.

MAIA, A.G. Custos e benefícios da recomposição florestal em bacias hidrográficas. In: SIMPÓSIO DE RESTAURAÇÃO ECOLÓGICA: NOVOS RUMOS, 6., São Paulo. Anais [...]. São Paulo: Governo do estado de São Paulo, Instituto de botânica, 2015.

MALHOTRA, Naresh K. Pesquisa de marketing: uma orientação aplicada. 3. ed. Porto Alegre: Bookmann, 2001.

\section{MILLENNIUM ECOSYSTEM ASSESSMENT. Relatório Síntese da Avaliação}

Ecossistêmica do Milênio: (Minuta Final - para ser copiada e editada). 2005. Disponível em: https://www.millenniumassessment.org/documents/document.446.aspx.pdf. Acesso em: 14 out. 2018.

PAIVA, Roberta Fernanda da Paz de Souza; COELHO, Rafael Campos. O programa Produtor de Água e Floresta de Rio Claro (RJ) enquanto ferramenta de gestão ambiental: o perfil e a percepção ambiental dos produtores inscritos. Revista Desenvolvimento e Meio Ambiente, Curitiba, v. 33, p. 51-62, 2015. Disponível em:

https://revistas.ufpr.br/made/article/view/36702. Acesso em: 3 nov. 2018.

PENSAMENTO VERDE. A relação entre revolução industrial e o meio ambiente. 2014. Disponível em: https://www.pensamentoverde.com.br/meio-ambiente/relacao-entrerevolucao-ambiental-e-meio-ambiente/. Acesso em: 1 nov. 2018.

PEREIRA, Celia Santos de Souza; ALVES SOBRINHO, Teodorico. Cenário mundial dos Pagamentos por Serviços Ambientais (PSAS) para conservação hídrica. Ambiência - Revista do Setor de Ciências Agrárias e Ambientais, Guarapuava, v. 13, n. 2, 2017. Disponível em: https://revistas.unicentro.br/index.php/ambiencia/article/viewFile/4572/3650 Acesso em: 22 out. 2018.

PINTO, Jorge de Souza et al. Diagnóstico e avaliação da eficiência da preservação do 
ambiente em Mato Grosso do Sul a partir da inclusão do pagamento de serviços ambientais. Revista Desenvolvimento e Meio Ambiente, Curitiba, v. 35, p. 255-240, 2015. Disponível em: https://revistas.ufpr.br/made/article/view/41238. Acesso em: 15 out. 2018.

PLAN VIVO. Scolel'te, México: Scolel'te is an ecosystem services programme focused on reforestation and forest management. 2019. Disponível em: http://www.planvivo.org/projectnetwork/scolelte-mexico/. Acesso em: 22 abr. 2019.

SOUSA, Joyce Silvestre de. Vegetação e recursos hídricos na bacia do Rio Claro - Minas Gerais: diagnóstico e instrumentos para gestão. 239 f. 2017. Tese (Doutorado em recursos hídricos e sistemas agrícolas) - Universidade Federal de Lavras, UFLA, 2017. Disponível em: http://repositorio.ufla.br/bitstream/1/21865/2/TESE_Vegeta\%C3\%A7\%C3\%A3o\%20e\%20re cursos $\% 20 \mathrm{~h} \% \mathrm{C} 3 \%$ ADdricos $\% 20 \mathrm{na} \% 20 \mathrm{Bacia} \% 20 \mathrm{do} \% 20 \mathrm{Rio} \% 20 \mathrm{Claro} \% 20 \% \mathrm{E} 2 \% 80 \% 93 \% 2$ 0Minas\%20Gerais\%3A\%20diagn\%C3\%B3stico\%20e\%20instrumentos\%20para\%20a\%20ges t\%C3\%A3o.pdf. Acesso em: 28 out. 2019.

WUNDER, Syen. CIFOR Occasional paper No. 42: Payments for environmental services: some nuts and bolts. Indonesia: CIFOR, 2005. 24 p. Disponível em:

https://www.cifor.org/publications/pdf_files/OccPapers/OP-42.pdf. Acesso em: 28 out. 2019. 